\title{
Health and Quality of Life of Bangladeshi Migrants in Melbourne-An Analysis with Four Multi-Attribute Utility and Three Subjective Wellbeing Instruments
}

\author{
Munir A. Khan ${ }^{1} \&$ Jeff Richardson ${ }^{2}$ \\ ${ }^{1}$ Research Fellow, Centre for Health Economics, Monash University, Australia \\ ${ }^{2}$ Foundation Director, Centre for Health Economics, Monash University, Australia \\ Correspondence: Munir A Khan, Centre for Health Economics, Monash University, Clayton, Victoria 3800, \\ Australia. Tel: 61-3-9905-0739. E-mail: Munir.Khan@monash.edu
}

Received: July 12, 2013

Accepted: August 2, 2013

Online Published: November 18, 2013

doi:10.5539/jms.v3n4p53

URL: http://dx.doi.org/10.5539/jms.v3n4p53

\begin{abstract}
The aim is to investigate the health and quality of life $(\mathrm{QoL})$ of Bangladeshi migrants using 7 Multi-Attribute instruments. Participants for this empirical study comprised Bangladeshi migrants living in Melbourne. Data were collected through a questionnaire survey. Respondents who completed the questionnaire were aged between 18 and 65 years old. Over $50 \%$ of the participants possessed excellent or very good health and $83 \%$ did not have any significant illness. Both males and females were found to be more overweight but less obese compared with the Australian population. Over $70 \%$ had low and $13 \%$ had high or very high levels of psychological distressas measured by the K10. The lifestyle of the migrants is distinct-about $80 \%$ never drank alcohol or smoked cigarettes. The recently developed AQoL-8D was the most sensitive to psychological distress, the personal wellbeing index and with BMI and had the highest correlation with EQ-5D and SF-6D within MAU instruments. Individual utility scores varied significantly at the individual level. The significant loss of QoL with increasing obesity and psychological distress are areas of concern for policy makers.
\end{abstract}

Keywords: qualityof life, MAU, SWB instruments, AQoL-8D, lifestyle, Bangladeshi migrants

\section{Introduction}

The health and quality of life of migrants has long been an area of interest for health economics researchers. It provides a fascinating insight into how people adapt to new environments and how they struggle to maintain old habits and customs without sacrificing what is important to them - in brief, their quality of life. Multi attribute (MA) instruments are a convenient and reliable way of conducting this research.

Numerous MA instruments are available to measure health related quality of life (HRQoL). These include a large number of psychometric, disease-specific instruments, as well as a small number of generic Multi Attribute Utility (MAU) instruments. These may be used to measure and evaluate the HRQoL of the general public and/or patients with or without the use of utility weights (Hawthorne, Richardson et al., 2003; Brazier, Roberts et al., 2004). With utility weights they may be used in economic analyses to produce the utility scores needed for the calculation of Quality Adjusted Life Years (QALYs), which are the unit of output in cost utility analysis (Torrance 1986). These multi attribute utility instruments (MAUI) include the Assessment of Quality of Life (AQoL)-8D, the EQ-5D (EuroQoL), the Short-Form Six-Dimension (SF-6D) and the Health Utilities Index (HUI 3). However, to date none of these instruments have been used for measuring the HRQoL of a small ethnic group, although such communities are known to have unique health profiles.

The overall aim of this paper is to examine the HRQoL of Bangladeshi migrants in Melbourne using seven MA quality of life instruments - the above four MAUI plus three subjective wellbeing (SWB) instruments: the Satisfaction with Life Scale (SWLS), the Personal Wellbeing Index (PWI) and the Kessler Psychological Distress Scale (K-10). These last three instruments do not have utility weights but nevertheless measure aspect of quality of life. The specific aims of this paper are threefold: i) to compare the QoL of the Bangladeshi community with the Australian population; ii) to explore different aspects of this community related to their adaptation to their environment; and iii) to examine and measure the HR-QoL of Bangladeshi migrants using MAU and subjective wellbeing instruments. 


\subsection{Description of Bangladesh-Born Migrants}

South Asian countries, particularly India, Pakistan, Bangladesh and Sri Lanka, which were formerly part of British India, have a history of migration dating back to the colonial period. In the last few decades migrants from South Asian countries have been settling down in developed countries including the USA, Canada, Western Europe and Australia. This movement is usually believed to be for reasons of employment, higher earnings, better education and training, better quality of life or greater political freedom (Sarmiento, 1991).

Bangladeshi migrants comprise a small community in Australia. Following the end of the 'White Australia Policy' in 1976, only 66 Victorians were born in Bangladesh. Within 15 years the community had increased sevenfold to 519. Between 1991 and 2001 there was a dramatic increase in the number of arrivals from Bangladesh. By 2001, 1,418 Bangladesh-born people lived in Victoria (Museum Victoria, 2009). In 2009 the Bangladeshi community living in Melbourne is estimated to be approximately 4,000.

For the purposes of this study, Bangladeshi migrants include people with Bangladeshi parents, whether born in Bangladesh or elsewhere. The Bangladeshi community in Victoria is currently the second largest in Australia, after New South Wales. It is mainly concentrated in the local government areas of Monash, Maribyrnong, Moreland and Wyndham, with a high proportion of Bangladeshi migrants working as professionals in the fields of education, health and community services. The majority of Bangladeshi migrants, particularly males, are professional and well educated and have entered Australia under the category of 'skilled migration' (Khan, 2003).

Recent literature suggests that migrants in general report poorer HRQoL in host countries. Immigrants from Western Europe, Canada, Australia and New Zealand have health profiles that are better than those of their US-born counterparts (Singh, 2001). It has been plausibly argued, that migrant health will eventually resemble that of the host population. Only in the short term, migrant health may differ from the host population (Benfante, 1992; Pudaric, 2000). However, when such studies are replicated in Australia, it is difficult to see the convergence of host and migrant health. It is believed that the non-convergence of migrants' health and wellbeing in Australia, particularly Bangladeshi migrants, is linked with a number of factors, including the process of adaptation and occupational adjustment in the host country.

The adaptation of social and cultural values in the host country by migrants has always been a challenge to the settlement process. It is suggested that social systems and other settings within migrant groups are central to the adaptation process as they provide opportunities for meaningful social engagement and participation in social roles (Sonn, 2002). These settings can be conceptualised as activity settings (O'Donnell, 1993) in which people spend time together and have opportunities and access to resources that facilitates the integration of identities and cultures into the new environment. Migrant groups create these settings to foster a sense of community and facilitate the adaptation and adjustment process. Length of residence is also identified as a determining factor for both social adaptation and the body mass index of the migrants in the host country (Sanchez-Vaznaugh et al., 2008).

With regards to Bangladeshi migrants, it has been reported that social and emotional disconnection, isolation and alienation, lack of recognition of professional skills, experiences of racism and discrimination, cultural incongruity, feelings of cultural uprooting and inadequate English language competency, contribute to psychological distress and difficulties in adjustment to life in Australia (Munib, 2006). The presence of co-ethnic communities, social support, networking, family cohesion, and retention of religious values and traditional cultural norms, has been associated with gradual acclimatization and successful resettlement in the host country. Networkings with the local Australian communities and acceptance of local cultural values have also been identified as important factors for promoting socio-cultural integration. In general, these factors appear to exert a protective effect against psychological distress in South-Asian migrants.

\subsection{Seven Multi-Attribute Quality of Life Instruments}

Selecting between preference-based MA instruments for measuring HRQoL in particular contexts is an important area for research. Even where instruments purport to measure the same thing, they may not be interchangeable. While some work has been done comparing the validity and sensitivity of alternative instruments (Hawthorne et al., 2003), to date no multi-instrument comparison has been made for a small ethnic community. In this paper seven multi-attribute quality of life instruments have been selected because of their widespread use and a prior suitability.

The AQoL-8D instrument was developed at the Centre for Health Economics (CHE) at Monash University. The instrument consists of the eight dimensions and 35 items. The number of items and the number of responses per item vary. The dimensions and items are summarised in Box 1. The full instrument may be obtained from the CHE 
website (http://www.buseco.monash.edu.au/centres/che/).

Box 1. AQoL-8D instrument

\begin{tabular}{|ll|}
\hline Dimension & Items \\
\hline Independent Living & 1. Household tasks; 2. Mobility outside the home; 3. Walking; 4. Self-care \\
Life Satisfaction & 5. Content of life; 6. Enthusiasm; 7. Degree of feeling happiness; 8. Pleasure \\
Mental Health & 9. Feelings of depression; 10. Trouble of sleeping; 11. Feeling of angry, 12. Self-harm 13. Feeling of \\
& despair; 14. Worry; 15. Sadness; 16. Tranquility/agitation \\
Coping & 17. Having enough energy; 18. Being in control; 19. Coping with problems \\
Relationships & 20. Enjoying relationship with family and friends; 21. Close relationship with family and friends; 22. \\
Social isolation, 23. Social exclusion; 24. Intimate relationship; 25. Family role; 26. Community role \\
27. Feeling burden; 28. Worthless, 29. Confidence \\
Pain & $\begin{array}{l}\text { 30. Experience of serious pain; 31. The degree of pain 32. The interference with usual activities caused } \\
\text { by pain }\end{array}$ \\
Senses & 33. Vision; 34. Hearing; 35. Communication
\end{tabular}

The EQ-5D (EuroQoL) is a standardised instrument which was developed by a multi-disciplinary group of researchers from seven centres across five countries for use as a measure of health outcome (EuroQoL Group 1990).

The SF-6D was derived from the SF-12 and SF-36. The SF-36 has become the most widely used measure of general health in clinical studies throughout the world. The SF-6D focuses more on social functioning, while the EQ-5D gives more weight to physical functioning. The SF-6D gives similar weight to physical and psycho-social health.

The Health Utilities Index Mark 3 (HUI 3) is a prominent measure of HRQoL and widely used in population health surveys, clinical studies and cost utility analyses, especially in Canada, where it originated. The HUI 3 has been used to assess health status in a number of chronic conditions.

The Kessler Psychological Distress Scale (K-10) dates from 1992. It has been widely used in the USA as well as in Australia. The K-10 scale is based on 10 questions (items) related to negative emotional states experienced by individuals during the past four week period. There are five response levels for each item based on the amount of time the respondent reports experiencing the particular problem.

The Personal Wellbeing Index (PWI) was developed from the Comprehensive Quality of Life Scale (ComQol). The PWI scale contains nine items relating to life satisfaction, each one corresponding to a quality of life domain. It comprises: standard of living, health, achieving in life, relationships, safety, community connectedness, future security, spirituality/religion and the level of satisfaction as a whole.

The Satisfaction with Life Scale (SWLS) uses five key statements associated with the level of satisfaction relating to the quality of life. Examples include: 'in most ways life is close to ideal'; 'the conditions of life are excellent'; 'satisfied with life'; 'so far gotten the things wanted in life'; and 'if I could live my life over, I would change almost nothing'.

The characteristics of these seven multi-attribute instruments, including the number of dimensions, items and response levels are reported in Table 1. This paper does not directly evaluate or assess the validity of these instruments but uses the instrument's score to examine the relationships between the instruments and self-reported quality of life. This is done by comparing the seven measures in terms of the quality of life score generated from the instruments. In the present analysis utility weights were employed for four MAU instruments and unweighted scores were used for SWB instruments. Utility weights for the MAU instruments were obtained from the relevant algorithms. 
Table 1. Characteristics of 7 the multi-attribute instruments

\begin{tabular}{llllllll}
\hline Instrument & Dimensions & No of items & $\begin{array}{l}\text { Response } \\
\text { level }\end{array}$ & $\begin{array}{l}\text { Unweighted } \\
\text { Min }\end{array}$ & Maximum & $\begin{array}{l}\text { Weighted } * * \text { Scores } \\
\text { Minimum }\end{array}$ & Maximum \\
\hline AQoL-8D & 8 & 35 & 4 to 6 & 0 & 1 & 0.42 & 1.0 \\
EQ-5D & $5^{*}$ & 5 & 3 & 0 & 1 & 0.60 & 1.0 \\
SF-6D & $6^{*}$ & 6 & 4 to 6 & 0 & 1 & 0.60 & 1.0 \\
HUI 3 & $8^{*}$ & 8 & 5 to 6 & 0 & 1 & 0.04 & 1.0 \\
K10 & $10^{*}$ & 10 & 5 & 0 & 1 & 0.35 & 1.0 \\
SWLS & $5^{*}$ & 5 & 7 & 0 & 1 & 0.00 & 1.0 \\
PWI & $9 *$ & 9 & 10 & 0 & 1 & 0.10 & 1.0 \\
\hline
\end{tabular}

* Number of Dimension is the same as number of items **AQoL-8D, EQ-5D, SF-6D and HUI3 use utility (or preference) weights.

The unweighted scores were obtained from the item responses from the participants using the following formula:

$$
\text { Score }=1-\left(\frac{X-X_{\min }}{X_{\text {max }}-X_{\text {min }}}\right)
$$

Where $\mathrm{x}=$ Individual's total score from summing the response category rank; $\mathrm{x}_{\min }=$ Instrument's total minimum score; $\mathrm{x}_{\max }=$ Instrument's total maximum score. This simple algorithm and relevant MAU utility algorithms result in values which vary between 1.0 (full health) and 0.0 (poorest health).

\section{Methods}

This is an empirical study where the data wascollected from primary sources. An open invitation to participate in the project which stated the brief aims and objectives of the study, eligibility, remuneration and how to participate. It was distributed throughout the Bangladeshi community through the leaders of community organisations, cultural groups, family and friends, and community businesses, eg grocery shops and restaurants. Three hundred hard copy questionnaires were posted or distributed among the potential participants in five SEIFA (Socio Economic Indicators for Areas) groups to obtain a representative sample. The contents of the questionnaire are summarised in Box 2.

Box 2. Contents of the questionnaire

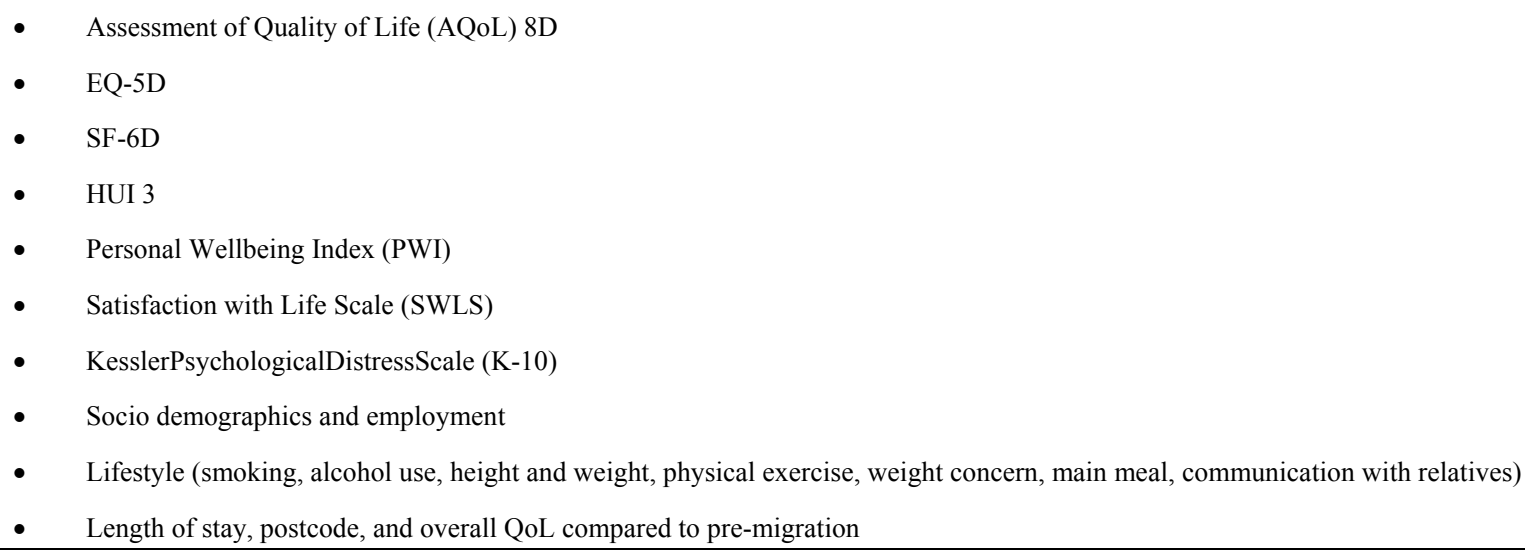

Upon agreement, people were given the registration form, explanatory statement and a soft copy of the questionnaire. When preferred, a hard copy of the questionnaire was posted to respondents with a pre-paid response envelope for its return. The questionnaire was also administered face to face among a sample of Bangladeshi migrants at different locations in Melbourne, including community and social functions, family gatherings and individual households. Secondary data also was collected from published and unpublished materials including the Australian Bureau of Statistics (ABS).

Upon receipt of the completed questionnaire from respondents, data was checked and edited before entry into SPSS (Statistical Package for the Social Sciences) for analysis. In the case of error or omission, the questionnaire 
was returned for completion. There was a random $20 \%$ data check on all variables. Analysis included comparison of descriptive statistics, correlation, ANOVA and regression.

\section{Results of Survey}

In total 166 people expressed interest in participating in the research, of whom 158 completed the questionnaire, constituting a response rate of $95 \%$. The response rate by question varied from a low of $98.7 \%$ (respondent's weight) to $100 \%$ for all other variables. The sample size of 158 permits a power of $80 \%$ and effect size of $22 \%(.22)$ at the 5\% level (using a two tailed test) (Burns \& Grove, 2001). Results reported below are based upon data from all 158 respondents.

\subsection{Socio-Demographic Characteristics}

Table 2 reports participants' demographic and social characteristics. There were more males (54\%) than females (46\%) and most of them were married (78\%), living with family (85\%) and were born in Bangladesh (96\%). The age distribution shows a similar proportion in each age group to the Australian population except for the larger number of young adults aged 25-34 and the much smaller proportion above the age of 55 (which reflects the recent history of immigration from Bangladesh).

Table 2. Demographics of the participants

\begin{tabular}{|c|c|c|c|c|c|}
\hline \multirow{2}{*}{ Variables } & \multirow{2}{*}{ Description } & \multirow{2}{*}{$\begin{array}{l}\text { Gender } \\
\text { Male }\end{array}$} & & \multicolumn{2}{|c|}{ Total } \\
\hline & & & Female & No & $\%$ \\
\hline Respondent & Gender & 53.8 & 46.2 & 158 & 100 \\
\hline \multirow{6}{*}{ Age Group } & $18-24$ years & 15.3 & 13.7 & 23 & 14.6 \\
\hline & $25-34$ years & 37.6 & 32.9 & 56 & 35.4 \\
\hline & $35-44$ years & 17.6 & 26 & 34 & 21.5 \\
\hline & $45-54$ years & 27.1 & 26 & 42 & 26.6 \\
\hline & $55-64$ years & 2.4 & 1.4 & 3 & 1.9 \\
\hline & Total & 85 & 73 & 158 & 100 \\
\hline \multirow{4}{*}{ Marital Status } & Married & 70.6 & 86.3 & 123 & 77.8 \\
\hline & Single & 28.2 & 11 & 32 & 20.3 \\
\hline & Divorced or Separated & 1.2 & 2.7 & 3 & 1.9 \\
\hline & Total & 85 & 73 & 158 & 100 \\
\hline \multirow{5}{*}{ Living arrangement } & By myself & 7.1 & 1.4 & 7 & 4.4 \\
\hline & $\begin{array}{l}\text { Family including } \\
\text { parents/husband/wife/partner/children }\end{array}$ & 75.3 & 95.9 & 134 & 84.8 \\
\hline & Friends/shared accommodation & 17.6 & 1.4 & 16 & 10.1 \\
\hline & Other & 0 & 1.4 & 1 & 0.6 \\
\hline & Total & 85 & 73 & 158 & 100 \\
\hline \multirow{6}{*}{ Country of Birth } & Australia & 2.4 & 1.4 & 3 & 1.9 \\
\hline & Bangladesh & 95.3 & 97.3 & 152 & 96.2 \\
\hline & Libya & 0 & 1.4 & 1 & 0.6 \\
\hline & Philippines & 1.2 & 0 & 1 & 0.6 \\
\hline & Other & 1.2 & 0 & 1 & 0.6 \\
\hline & Total & 85 & 73 & 158 & 100 \\
\hline \multirow{6}{*}{ SEIFA Group } & 1 & 20.1 & 16.4 & 29 & 18.4 \\
\hline & 2 & 9.4 & 8.2 & 14 & 8.9 \\
\hline & 3 & 30.6 & 27.4 & 46 & 29.1 \\
\hline & 4 & 30.6 & 34.2 & 51 & 32.3 \\
\hline & 5 & 9.4 & 13.7 & 18 & 11.4 \\
\hline & Total & 85 & 73 & 158 & 100 \\
\hline
\end{tabular}

The geographical distribution of participants according to SEIFA group which is defined by the Socio-Economic Status (SES) of the respondents' postcode, indicated that the majority of Bangladeshi migrants (57\%) were from the lower three SEIFA groups ( 1 to 3 ) and the remaining $43 \%$ were from the higher groups (4 and 5). A lower number indicates more disadvantages and a higher number indicates a higher level of SES.

Education, employment and income of the participants are reported in Table 3. Most of the migrants are well qualified. About $91 \%$ had graduate or postgraduate degrees (compared to $30 \%$ of the Australian population). Only $6 \%$ had only completed year 12 or equivalent. About $50 \%$ were employed full time, $24 \%$ were part-time and $12 \%$ were unemployed. Males had more full-time and females had more part-time employment. About two-thirds of 
males and one third of females had full-time a further third of females and $13 \%$ of males had a part-time position. The 12\% unemployment rate for Bangladesh-born migrants was higher than the Australian national unemployment rate $(5.8 \%$ in July 2009$)$. The unemployment rate for females was nearly double $(15 \%)$ that of males $(8.3 \%)$. About $33 \%$ of the respondents had a weekly household income of $\$ 650$ to $\$ 1399$ and $42 \%$ had income more than $\$ 1400$ per week.

Table 3. Education, employment and income distribution of the participants

\begin{tabular}{|c|c|c|c|c|c|}
\hline \multirow{2}{*}{ Variables } & \multirow{2}{*}{ Description } & \multicolumn{2}{|c|}{ Gender } & \multicolumn{2}{|c|}{ Total } \\
\hline & & Male & Female & No & $\%$ \\
\hline \multirow{7}{*}{ Highest Level of Education } & High school & 1.2 & 0 & 1 & 0.6 \\
\hline & Completed year 12 or equivalent & 2.4 & 9.6 & 9 & 5.7 \\
\hline & Certificate/ Trade qualification & 1.2 & 0 & 1 & 0.6 \\
\hline & Advanced diploma/ TAFE & 0 & 4.1 & 3 & 1.9 \\
\hline & Bachelor/graduate diploma & 27.1 & 46.6 & 57 & 36.1 \\
\hline & Postgraduate degree & 68.2 & 39.7 & 87 & 55.1 \\
\hline & Total & 85 & 73 & 158 & 100 \\
\hline \multirow{8}{*}{ Employment Status } & Full-time: self-employed or employee & 66.7 & 30.1 & 78 & 49.7 \\
\hline & Part-time or casual: self-employed or employee & 13.1 & 35.6 & 37 & 23.6 \\
\hline & Unemployed, seeking work & 8.3 & 15.1 & 18 & 11.5 \\
\hline & Not in the labour force/retired/pensioner & 0 & 1.4 & 1 & 0.6 \\
\hline & Full time carer & 1.2 & 0 & 1 & 0.6 \\
\hline & Student & 9.5 & 9.6 & 15 & 9.6 \\
\hline & Other & 1.2 & 8.2 & 7 & 4.5 \\
\hline & Total & 84 & 73 & 157 & 100 \\
\hline \multirow{7}{*}{ Gross household income } & Below $\$ 150.00 \mathrm{pw}$ & 4.8 & 4.2 & 7 & 4.5 \\
\hline & $\$ 150$ to $\$ 349 \mathrm{pw}$ & 6 & 2.8 & 7 & 4.5 \\
\hline & $\$ 350$ to $\$ \$ 649 \mathrm{pw}$ & 15.5 & 15.3 & 24 & 15.4 \\
\hline & $\$ 650$ to $\$ 1399 \mathrm{pw}$ & 36.9 & 29.2 & 52 & 33.3 \\
\hline & $\$ 1400$ to $\$ 1999 \mathrm{pw}$ & 15.5 & 27.8 & 33 & 21.2 \\
\hline & Above $\$ 2000$ pw & 21.4 & 20.8 & 33 & 21.2 \\
\hline & Total & 84 & 72 & 156 & 100 \\
\hline
\end{tabular}

\subsection{Respondent's Self-Reported Health and Illness}

Self-reported health, general health conditions, illness and psychological distress are reported in the following sections. When a participant was asked to rate their health, for someone of their age, $13 \%$ reported 'excellent', $40 \%$ responded 'very good', 37\% reported 'good', and 7.6\% said 'fair'. Only 3.2\% reported that they had 'poor' health and none had 'very poor' health (Table 4). Within the gender group, males and females had similar health.

Table 4. Self-reported health of the migrants

\begin{tabular}{|c|c|c|c|c|c|}
\hline \multirow{2}{*}{ Current level of health } & \multirow{2}{*}{ Response } & \multicolumn{2}{|l|}{ Gender } & \multicolumn{2}{|c|}{ Total } \\
\hline & & Male & Female & No & $\%$ \\
\hline \multirow{6}{*}{$\begin{array}{l}\text { How would you rate your current level of health, for } \\
\text { someone of your age? }\end{array}$} & Excellent & 7.1 & 19.2 & 20 & 12.7 \\
\hline & Very good & 41.2 & 38.4 & 63 & 39.9 \\
\hline & Good & 40 & 32.9 & 58 & 36.7 \\
\hline & Fair & 7.1 & 8.2 & 12 & 7.6 \\
\hline & Poor & 4.7 & 1.4 & 5 & 3.2 \\
\hline & Total & 85 & 73 & 158 & 100 \\
\hline
\end{tabular}

However, the self-assessment as 'excellent' was much more common for females (19\%) than males (7\%) while males were slightly more inclined to report 'very good' and 'good' conditions.

About three quarters of all participants believed they were 'as healthy as anybody' and 'do not get sick easier than other people'. Only $8 \%$ expected their health to get worse. When asked 'Do you currently have a significant illness?' $83 \%$ responded 'no' and 17\% said 'yes'. Within the gender group males and females had similar responses (Table 5). 
Table 5. Whether suffer from any significant illness

\begin{tabular}{|c|c|c|c|c|c|}
\hline \multirow{2}{*}{ When asked } & \multirow{2}{*}{ Response } & \multicolumn{2}{|l|}{ Gender } & \multicolumn{2}{|c|}{ Total } \\
\hline & & Male & Female & No & $\%$ \\
\hline \multirow{3}{*}{ Do you currently have a significant illness? } & No & 82.4 & 83.6 & 131 & 82.9 \\
\hline & Yes & 17.6 & 16.4 & 27 & 17.1 \\
\hline & Total & 85 & 73 & 158 & 100 \\
\hline
\end{tabular}

Self-reported health was also analysed according to participant's age, education and income. Respondents who reported 'excellent' health were aged 34 years or less $(75 \%)$, graduate or postgraduate degree holders $(80 \%)$, and had income more than $\$ 1400$ or more (37\%). Fair and poor health is associated with older age groups (35 to 54 years) and low income (less than $\$ 1400 \mathrm{pw}$ ) people.

The level of psychological distress as measured by the K10 is reported in Table 6 by gender. The Victorian Population Health Survey (2001) adopted the following cut-off scores for different levels of psychological distress: 10-19 (Low); 20-24 (Moderate), 25-29 (High); and 30-50 (Very High). The data show that most of the Bangladeshi participants had low levels of psychological distress - $68 \%$ of males and $73 \%$ of females. But the percentages are smaller than for the better off Australian population ( $86 \%$ for males and $80 \%$ for females). In contrast, more males and females had moderate distress and marginally more had 'high' or 'very high' levels of distress than in the Australian population (Table 6).

Table 6. Level of psychological distress by gender

\begin{tabular}{|c|c|c|c|c|c|c|}
\hline \multirow{2}{*}{$\begin{array}{l}\text { Level of Psychological } \\
\text { Distress }\end{array}$} & \multirow{2}{*}{$\begin{array}{l}\text { Gender } \\
\text { Male }\end{array}$} & \multicolumn{3}{|c|}{ Total } & \multicolumn{2}{|c|}{ National Health Survey 2001} \\
\hline & & Female & No & $\%$ & Male & Female \\
\hline Low $(10-19)$ & 68.2 & 72.6 & 111 & 70.3 & 85.8 & 79.6 \\
\hline Moderate (20-24) & 16.5 & 17.8 & 27 & 17.1 & 8.3 & 10.6 \\
\hline High $(25-29)$ & 9.4 & 8.2 & 14 & 8.9 & 3.1 & 5.5 \\
\hline Very High (30-50) & 5.9 & 1.4 & 6 & 3.8 & 2.7 & 4.4 \\
\hline Total & 85 & 73 & 158 & 100 & 100 & 100 \\
\hline
\end{tabular}

\subsection{Lifestyle of the Migrants}

The lifestyle of Bangladeshi migrants was defined to include physical exercise, concern with own weight, Body Mass Index (BMI), alcohol use, smoking behaviour, main meal, social participation and engagement, and communication with relatives. The lifestyles of the participants, so defined, are reported in Tables 7 and 8 . Table 7 shows that Bangladeshi migrants were very concerned (28\%) with their weight (either all of the time or most of the time) but did not do intense regular exercise. Only $11 \%$ (15\% male $7 \%$ female) of the respondents reported that they had regular intense physical exercise, and $74 \%$ had moderate exercise. About eight in ten reported that they never drank alcohol or smoked cigarettes. The proportion of females reporting non-smoking and non-drinking was a little higher than males. It appears that they acquired these habits from their parents because nearly all of the respondent's parents ( $83 \%$ and $93 \%$ respectively) did not smoke or drink alcohol. About $97 \%$ of smokers started smoking with friends and close associates. About $91 \%$ of respondents said they usually eat home-cooked traditional Bangladeshi meals on most days. Most of the Bangladesh-born migrants (82\%) had daily or weekly telephone or physical contact with family members who are not living with them.

In Australia, $16.4 \%$ of adults ( $17.8 \%$ of males and $15.1 \%$ of females) were reported as obese in 2004-05 and 3 in 5 adults (61\%) were either overweight or obese in 2007-08 (AIHW 2010). The BMI of the respondents is reported in Table 8. This shows that about $50 \%$ of Bangladeshi migrants were either overweight or obese. Males were found to be more overweight than females. Both males and females were found to be more overweight but less obese when compared with the Australian population.

Bangladeshi migrants are well connected with the Australian community. When asked about participation, 37\% said they help a local group as a volunteer and $49 \%$ had attended a local community event in the past six months. About 27 were active member of a local club, 17\% were on a local group management committee and 19\% had participated in community action to deal with an emergency in the past 3 years.

\subsection{Effect of Migration}

Length of stay in the host country is important for the adaptation process and occupational adjustment of migrants. The majority of Bangladeshi migrants are relatively new in Australia. About $54 \%$ of the respondents had lived less 
than 10 years and $46 \% 10$ or more years in Australia. The BMI and psychological distress level of migrants were analysed by the length of stay (using ANOVA). Table 9 reports the results. It reveals that length of stay has a significant effect on BMI and K-10 scores. The mean varies from a low of 23.3 in the 10 to 14 year category to a high of 26.5 in the 5-9 year group for BMI, and 13.5 in the 15+ years to a high of 17.8 in the 5 year group for the $\mathrm{K}-10$ score (sig 0.001 and 0.005 respectively).

Finally, migrants' overall quality of life compared to their pre-migration situation was analysedwith a logit regression using socio-economic status and lifestyle as explanatory variables. The dependent variable had a value of 1.00 for an improved life as compared with pre-migration. The independent variables include the age groups $($ agegp $1=18-24 \mathrm{yrs} ;$ agegp2 $=25-34 \mathrm{yrs}$; agegp3 $=35-44 \mathrm{yrs}$; agegp4= 45yrs +$)$, levels of education $(\mathrm{edu} 1=$ non graduate; edu2 $=$ graduate; edu $3=$ postgraduate $),$ employment $(\mathrm{emp} 1=$ full-time; emp $2=$ part-time or casual; emp3 = unemployed; emp $4=$ not in the labour force; emp $5=$ student), income (income $1=<\$ 350 \mathrm{pw}$; income $2=$ $\$ 350-\$ 649$; income $3=\$ 650-\$ 1399$; income $4=\$ 1400-\$ 1999$; income $5=\$ 2000+$ ), length of stay (length $1=<5 \mathrm{yrs}$; length $2=5$-9yrs; length $3=10-14 \mathrm{yrs}$; length $4=15 \mathrm{yrs}+$ ), and bmi $(\mathrm{bmi} 1=$ underweight; bmi $2=$ normal; bmi $3=$ overweight; bmi4= obese). Table 10 reports the result of the analyses. This indicates that age, education, employment and income are all associated with the likelihood of a person's QoL being greater than pre-migration. As expected, adaptation is more likely amongst the young, well educated, the employed and those with higher incomes. Unexpectedly the length of time since migration was not strongly associated, possibly reflecting a correlation with employment. BMI and smoking had no effect.

Table 7. Lifestyle of Bangladesh-born migrants by gender

\begin{tabular}{|c|c|c|c|c|c|}
\hline \multirow[t]{2}{*}{ Variables } & \multirow[t]{2}{*}{ Response } & \multicolumn{2}{|l|}{ Gender } & \multicolumn{2}{|l|}{ Total } \\
\hline & & Male & Female & No & $\%$ \\
\hline \multirow{4}{*}{$\begin{array}{l}\text { Do you do any physical exercise during } \\
\text { leisure time? }\end{array}$} & Regular - Intense & 15.3 & 6.8 & 18 & 11.4 \\
\hline & Moderate - Sometimes & 68.2 & 80.8 & 117 & 74.1 \\
\hline & Inactive - Never & 16.5 & 12.3 & 23 & 14.6 \\
\hline & Total & 85 & 73 & 158 & 100 \\
\hline \multirow[t]{6}{*}{ Are you concerned with your weight? } & All of the time & 9.4 & 15.1 & 19 & 12 \\
\hline & Most of the time & 21.2 & 9.6 & 25 & 15.8 \\
\hline & Some of the time & 40 & 38.4 & 62 & 39.2 \\
\hline & A little of the time & 20 & 19.2 & 31 & 19.6 \\
\hline & None of the time & 9.4 & 17.8 & 21 & 13.3 \\
\hline & Total & 85 & 73 & 158 & 100 \\
\hline \multirow{5}{*}{$\begin{array}{l}\text { How often do you have a drink } \\
\text { containing alcohol? }\end{array}$} & Never & 70.6 & 82.2 & 120 & 75.9 \\
\hline & Monthly or less & 14.1 & 11 & 20 & 12.7 \\
\hline & 2-3 times a month & 10.6 & 6.8 & 14 & 8.9 \\
\hline & 2-3 times a week & 4.7 & 0 & 4 & 2.5 \\
\hline & Total & 85 & 73 & 158 & 100 \\
\hline \multirow[t]{3}{*}{ Do either of your parents drink alcohol? } & Yes & 5.9 & 8.2 & 11 & 7 \\
\hline & No & 94.1 & 91.8 & 147 & 93 \\
\hline & Total & 85 & 73 & 158 & 100 \\
\hline \multirow[t]{5}{*}{ What is your current smoking status? } & Never smoked & 62.4 & 97.3 & 124 & 78.5 \\
\hline & Smoking daily & 12.9 & 0 & 11 & 7 \\
\hline & Smoking occasionally & 9.4 & 2.7 & 10 & 6.3 \\
\hline & Now quit & 15.3 & 0 & 13 & 8.2 \\
\hline & Total & 85 & 73 & 158 & 100 \\
\hline \multirow[t]{3}{*}{ With whom did you first smoke? } & By myself & 3.3 & 0 & 1 & 3.1 \\
\hline & With friends/close associates & 96.7 & 100 & 31 & 96.9 \\
\hline & Total & 30 & 2 & 32 & 100 \\
\hline \multirow[t]{3}{*}{ Do either of your parents smoke? } & Yes & 20 & 13.7 & 27 & 17.1 \\
\hline & No & 80 & 86.3 & 131 & 82.9 \\
\hline & Total & 85 & 73 & 158 & 100 \\
\hline
\end{tabular}




\begin{tabular}{|c|c|c|c|c|c|}
\hline \multirow[t]{5}{*}{$\begin{array}{l}\text { What do you usually take as your main } \\
\text { meal in most days? }\end{array}$} & $\begin{array}{l}\text { Home cooked traditional Bangladeshi } \\
\text { meal (rice/curry etc) }\end{array}$ & 89.4 & 93.2 & 144 & 91.1 \\
\hline & $\begin{array}{l}\text { Aussie food (steak, chicken, sausages, } \\
\text { bread, mashed potato }\end{array}$ & 4.7 & 4.1 & 7 & 4.4 \\
\hline & $\begin{array}{l}\text { Different ethnic traditional food at } \\
\text { restaurant }\end{array}$ & 4.7 & 2.7 & 6 & 3.8 \\
\hline & $\begin{array}{l}\text { Take away food from fast-food } \\
\text { restaurant }\end{array}$ & 1.2 & 0 & 1 & 0.6 \\
\hline & Total & 85 & 73 & 158 & 100 \\
\hline \multirow{6}{*}{$\begin{array}{l}\text { How often do you see or talk to family } \\
\text { members other than those who are living } \\
\text { with you? }\end{array}$} & Daily & 25.9 & 30.1 & 44 & 27.8 \\
\hline & Every week & 52.9 & 54.8 & 85 & 53.8 \\
\hline & Every month & 18.8 & 9.6 & 23 & 14.6 \\
\hline & Every few months & 0 & 5.5 & 4 & 2.5 \\
\hline & Seldom or never & 2.4 & 0 & 2 & 1.3 \\
\hline & Total & 85 & 73 & 158 & 100 \\
\hline
\end{tabular}

Table 8. BMI of Bangladesh-born migrants by gender

\begin{tabular}{lllllll}
\hline \multirow{2}{*}{ BMI Categories } & Gender & \multicolumn{2}{c}{ Total } & \multicolumn{2}{c}{ Australian population 2007 } \\
& Male & Female & No & \% & Male (\%) & Female (\%) \\
\hline Underweight $(<20)$ & 3.6 & 9.7 & 10 & 6.4 & 1.1 & 4.6 \\
Normal (20.0-24.99) & 41.7 & 47.2 & 69 & 44.2 & 40 & 50.8 \\
Overweight (25.0-29.99) & 45.2 & 37.5 & 65 & 41.7 & 41.3 & 26.2 \\
Obese (30+) & 9.5 & 5.6 & 12 & 7.7 & 17.6 & 18.5 \\
Total & 84 & 72 & 156 & 100 & & \\
\hline
\end{tabular}

Table 9. Effect of length of stay on BMI and psychological distress

\begin{tabular}{|c|c|c|c|c|c|c|c|c|c|c|}
\hline \multirow{2}{*}{ Variables } & \multirow{2}{*}{ Length of stay } & \multirow{2}{*}{$\mathbf{N}$} & \multirow{2}{*}{ Mean } & \multirow{2}{*}{ SD } & \multirow{2}{*}{ SE } & \multicolumn{2}{|c|}{ 95\% CI for Mean } & \multirow{2}{*}{ Min } & \multirow{2}{*}{$\operatorname{Max}$} & \multirow{2}{*}{ Sig. } \\
\hline & & & & & & LB & UB & & & \\
\hline \multirow{5}{*}{ Body Mass Index } & Less than 5 years & 39 & 24.6 & 3.3 & 0.5 & 23.5 & 25.6 & 17.3 & 38.4 & \multirow{5}{*}{0.001} \\
\hline & 5 to 9 years & 45 & 26.5 & 4.1 & 0.6 & 25.2 & 27.7 & 18.4 & 40.1 & \\
\hline & 10 to 14 years & 27 & 23.3 & 2.8 & 0.5 & 22.2 & 24.4 & 18 & 28.5 & \\
\hline & 15 years + & 45 & 25.8 & 3.4 & 0.5 & 24.8 & 26.8 & 18.8 & 37.9 & \\
\hline & Total & 156 & 25.2 & 3.7 & 0.3 & 24.7 & 25.8 & 17.3 & 40.1 & \\
\hline \multirow{5}{*}{ K10 Score } & Less than 5 years & 40 & 17.8 & 6.9 & 1.1 & 15.5 & 20 & 10 & 36 & \multirow{5}{*}{0.005} \\
\hline & 5 to 9 years & 46 & 16.6 & 6.2 & 0.9 & 14.8 & 18.4 & 10 & 31 & \\
\hline & 10 to 14 years & 27 & 17.4 & 6.5 & 1.3 & 14.8 & 20 & 10 & 32 & \\
\hline & 15 years + & 45 & 13.5 & 4.2 & 0.6 & 12.2 & 14.7 & 10 & 25 & \\
\hline & Total & 158 & 16.1 & 6.1 & 0.5 & 15.2 & 17.1 & 10 & 36 & \\
\hline
\end{tabular}


Table 10. Logistic regression of migrants' quality of life and some socio-economic and lifestyle variables dependent: life has improved $=1$

\begin{tabular}{|c|c|c|c|c|c|c|}
\hline Logistic regr & & & & & $\mathrm{Nu}$ & $\mathrm{fobs}=145$ \\
\hline & & & & & & $23)=44.22$ \\
\hline & & & & & & $\mathrm{ii}^{2}=0.0049$ \\
\hline Log likelihoo & $=-46.0891$ & & & & & $\mathrm{R}^{2}=0.3242$ \\
\hline QoL & Coef. & Std. Err. & Z & $\mathrm{P}>|\mathrm{z}|$ & {$[95 \%$} & iterval] \\
\hline agegp2 & 3.824 & 1.361 & 2.81 & 0.005 & 1.158 & 6.491 \\
\hline agegp3 & 4.132 & 1.429 & 2.89 & 0.004 & 1.332 & 6.933 \\
\hline agegp4 & 3.610 & 1.472 & 2.45 & 0.014 & 0.724 & 6.495 \\
\hline edu2 & -2.513 & 1.333 & -1.88 & 0.059 & -5.126 & 0.101 \\
\hline edu3 & -5.007 & 1.709 & -2.93 & 0.003 & -8.356 & -1.658 \\
\hline emp1 & -16.711 & 1.363 & -12.26 & 0.000 & -19.383 & -14.039 \\
\hline emp2 & -18.127 & 1.385 & -13.08 & 0.000 & -20.842 & -15.412 \\
\hline emp3 & -15.724 & . & . & . & . & . \\
\hline emp4 & -17.008 & 1.648 & -10.32 & 0.000 & -20.238 & -13.778 \\
\hline emp5 & -17.264 & 1.397 & -12.36 & 0.000 & -20.003 & -14.526 \\
\hline income1 & 3.896 & 2.736 & 1.42 & 0.154 & -1.466 & 9.258 \\
\hline income 2 & 3.938 & 2.767 & 1.42 & 0.155 & -1.485 & 9.360 \\
\hline income 3 & 6.180 & 2.905 & 2.13 & 0.033 & 0.486 & 11.874 \\
\hline income4 & 5.912 & 2.998 & 1.97 & 0.049 & 0.036 & 11.788 \\
\hline income 5 & 5.425 & 2.954 & 1.84 & 0.066 & -0.365 & 11.215 \\
\hline length1 & 2.215 & 1.306 & 1.7 & 0.090 & -0.345 & 4.775 \\
\hline length2 & -0.635 & 1.033 & -0.61 & 0.539 & -2.659 & 1.390 \\
\hline length4 & 1.045 & 1.039 & 1.01 & 0.314 & -0.992 & 3.082 \\
\hline bmi1 & 2.365 & 2.194 & 1.08 & 0.281 & -1.936 & 6.666 \\
\hline bmi2 & 3.201 & 2.063 & 1.55 & 0.121 & -0.842 & 7.244 \\
\hline bmi3 & 3.121 & 2.109 & 1.48 & 0.139 & -1.012 & 7.255 \\
\hline bmi4 & 1.855 & 2.298 & 0.81 & 0.419 & -2.649 & 6.359 \\
\hline smok2 & -0.121 & 0.852 & -0.14 & 0.887 & -1.791 & 1.549 \\
\hline _cons & 11.123 & 3.835 & 2.9 & 0.004 & 3.607 & 18.639 \\
\hline
\end{tabular}

Note: 0 failures and 1 success completely determined.

\section{Quality of Life of Bangladeshi Migrants}

\subsection{Distribution of Scores}

Table 11 reports the summary statistics and QoL scores for the seven QoL instruments. The first 4-EQ-5D, HUI 3, SF-6D and AQoL-8D are collectively referred to as the MAUI (MAU instruments); the remaining 3 as 'subjective well-being' (SWB) instruments and do not purport to measure 'utility' as economists use this term. The mean values of the former group are very similar, ranging from 0.85 (AQoL-8D) to 0.92 (EQ-5D). Standard errors are similar except for HUI 3 which is 50 percent above the others. Minimum scores vary significantly with HUI 3 again the outlier. The greatest discrepancy is in the number of individuals assigned the maximum score (ceiling effects). Both EQ-5D and HUI 3 had 91 and 59 such respondents or 57.6 and 37.3 percent of the total grouprespectively. SF-6D and AQoL-8D had 20.3 and 4.4 percent respectively. The two satisfaction scales had 4.4 and 5.1 respectively and the psychiatric K-10, 19.6 percent. These results indicate that EQ-5D and HUI 3 do not 
reflect variation in life satisfaction near the ceiling. These results are shown in Figure 1.

Table 11. Summary statistics and mean QoL scores for Bangladeshi migrants by instrument

\begin{tabular}{llllllll}
\hline Description & EQ-5D & HUI3 & SF-6D & AQoL-8D & PWI & SWLS & K-10 \\
\hline Mean & 0.92 & 0.89 & 0.86 & 0.85 & 0.75 & 0.71 & 0.85 \\
SE & 0.008 & 0.013 & 0.008 & 0.009 & 0.013 & 0.016 & 0.012 \\
Median & 1 & 0.95 & 0.88 & 0.87 & 0.78 & 0.75 & 0.9 \\
(IQR) & 0.17 & 0.15 & 0.14 & 0.14 & 0.18 & 0.16 & 0.25 \\
Min & 0.60 & -0.04 & 0.60 & 0.42 & 0.10 & 0.00 & 0.35 \\
Max & 1.00 & 1.00 & 1.00 & 1.00 & 1.00 & 1.00 & 1.00 \\
\% Score = Max & 57.6 & 37.3 & 20.3 & 4.4 & 4.4 & 5.1 & 19.6 \\
(Ceiling effect) & & & & & & & \\
\hline
\end{tabular}

In order to determinethe relationship between instruments correlations were estimated between the 4 utility weighted MAU and 3 unweighted SWB instruments and an analysis undertaken to determine instrument sensitivity near full health. Table 12 reports the correlation coefficients matrix for seven instruments. Although a bivariate correlation is only a simple measure of the relationships it is revealing. In all cases the correlations were significant at the 0.01 level. The last column of Table 12 indicates the instrument with which an instrument correlated most highly reveals that the AQoL-8D correlates most highly with EQ5D, SF-6D, SWLS and K-10. AQoL-8D has also the highest overall average correlation suggesting that it was the most suitable instrument for subsequent analysis.

Table 12. Correlation of 7 measures (4 MAU weighted and 3 SWB unweighted)

\begin{tabular}{|c|c|c|c|c|c|c|c|c|}
\hline \multirow[b]{2}{*}{ Measures } & \multicolumn{7}{|c|}{ Correlations } & \multirow{2}{*}{$\begin{array}{l}\text { Highest } \\
\text { correlation } \\
\text { with: }\end{array}$} \\
\hline & 1 & 2 & 3 & 4 & 5 & 6 & 7 & \\
\hline 1. EQ-5D & 1 & & & & & & & AQoL-8D \\
\hline 2. HUI3 & $.502^{* *}$ & 1 & & & & & & SF-6D \\
\hline 3. SF6D & $.558^{* *}$ & $.586^{* *}$ & 1 & & & & & AQoL-8D \\
\hline 4. AQoL-8D & $.610^{* *}$ & $.531^{* *}$ & $.593^{* *}$ & 1 & & & & EQ-5D \\
\hline Average (1-4) & 0.56 & 0.54 & 0.58 & 0.58 & & & & \\
\hline 5. PWI & $.452^{* *}$ & $.521^{* *}$ & $.476^{* *}$ & $.496^{* *}$ & 1 & & & HUI3 \\
\hline 6. SWLS & $.395^{* *}$ & $.477^{* *}$ & $.348^{* *}$ & $.503^{* *}$ & $.534^{* *}$ & 1 & & AQoL-8D \\
\hline 7. $\mathrm{K}-10$ & $.567^{* *}$ & $.456^{* *}$ & $.514^{* *}$ & $.668^{* *}$ & $.460^{* *}$ & $.440^{* *}$ & 1 & AQoL-8D \\
\hline Average (1-7) & .51 & .51 & .51 & .57 & .49 & .45 & .52 & \\
\hline
\end{tabular}

** Correlation is significant at the 0.01 level (2-tailed).

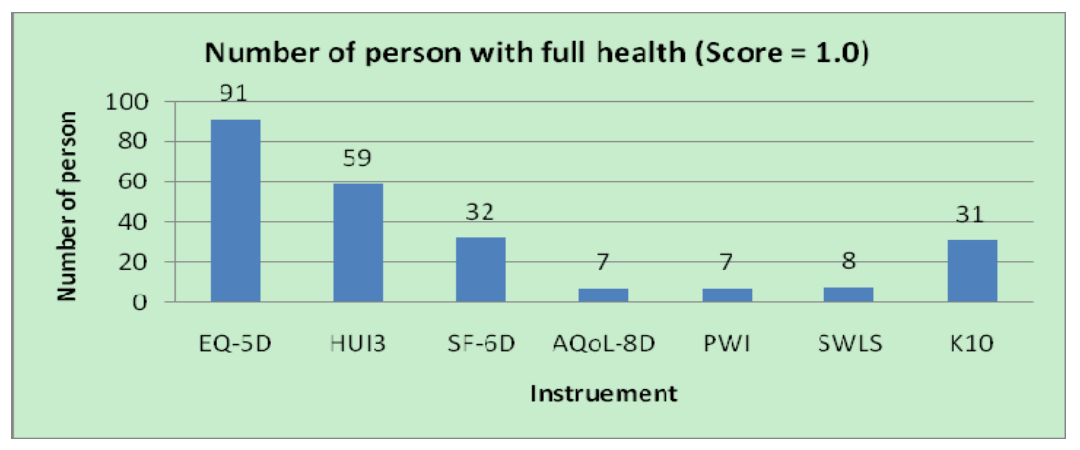

Figure 1. Comparison of full health by 7 MA instruments $(n=158)$

\subsection{Effect of BMI and Psychological Distress on Quality of Life of Small Ethnic Community}

Figure 2 and Figure 3 plots the regression line of AQoL-8D on K-10 and BMI respectively. As K-10 increases from 12 to 30 the trend line predicts a decrease in AQoL-8D mean utility scores from .9 to .67 (Figure 2). Similarly 
when BMI increases from 24 to 30 the trend line also predict a decrease in AQoL-8D mean utility score of about .042 or about 5 percent of the mean AQoL-8D utility (Figure 3). Over a 30 year period the predicted AQoL-8D utilities imply a significant amount of increase in QALYs at the lower psychological distress scale (K-10) and at lower BMI.

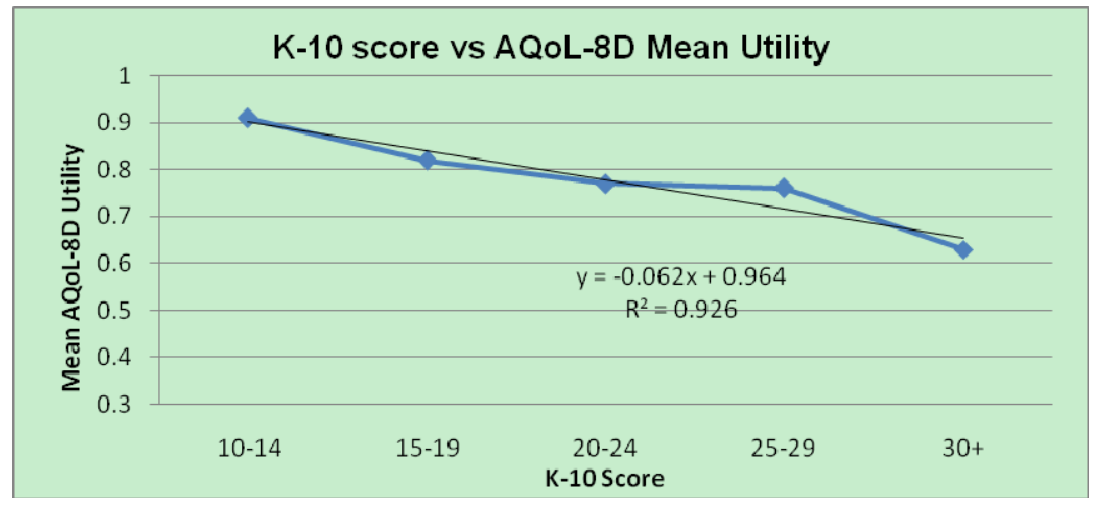

Figure 2. Mean K-10 vs AQoL-8D utility score

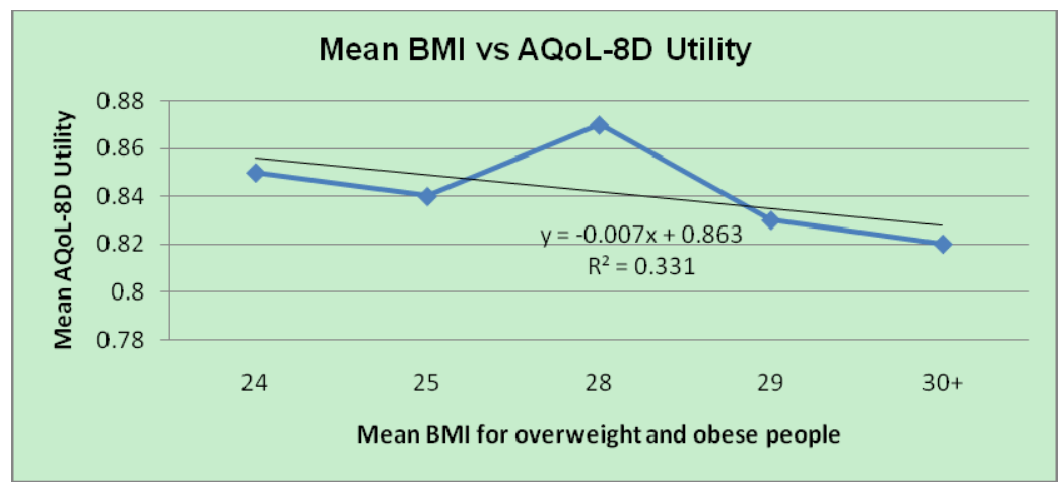

Figure 3. Mean BMI vs AQoL-8D utility score

\section{Discussion}

This paper examined the quality of life - particularly, the health-related quality of life - of Bangladeshi migrants living in Melbourne, Australia, using 7 multi-attribute (MA) instruments. The socio-economic and lifestyle characteristics of the migrants have been analysed to throw light on the process of adaptation and adjustment in the host country. The instruments employed in this study vary substantially in terms of the number of dimensions employed, the items and response levels, and the maximum and minimum possible scores (Table 1).

The analysis of the sample indicated that gender, age and SEIFA distribution are al well represented. The higher proportion of middle aged respondents (compared to the Australian population) is due to the selection of particular age groups (18 to 65 years) for the study. Most of the respondents were married and had a family (Table 2). They were well educated, employed either full-time or part-time and had upper-end gross household incomes (Table 3).

The results indicate that the vast majority of Bangladeshi migrants are relatively healthy and have no significant illness over and above the Australian norm. The self-reported health conditions reinforce this conclusion. However, a relatively high level of psychological distress among this community is consistent with prior findings (Munib, 2006).

The analysis of lifestyle characteristics of the migrants indicated that the Bangladeshi community is different from the Australian general population. More than three quarters did not smoke or drink alcohol. More than $90 \%$ ate home-cooked traditional Bangladeshi meals (Table 7). All these lifestyle aspects are associated with the quality of life, including health-related quality of life.

About $50 \%$ of Bangladesh-born migrants were either overweight or obese and only moderately integrated with the 
Australian community (Table 8 ). The analysis of time since migration, BMI and psychological stress indicated a significant effect the latter variables on the former (Table 9). However, this is not reflected in the multivariate analysis of overall QoL. But the result is consistent with previous results reporting the effects on BMI of education, gender and ethnicity (Sanchez-Vaznaughet al., 2008).

Results of the $7 \mathrm{MA}$ instrument comparisons indicated that all were highly correlated. The correlation matrix indicates that the recently developed AQoL-8D was most strongly correlated with the K-10, SF-6D, EQ-5D and PWI. In spite of their correlations, each of the instruments produced different results in terms of the non-weighted QoL scores. The wide variation is probably due to the varying number of dimensions, items and response levels. The range of scores was, however, limited by the overall good health of the respondents. This was reflected in the insensitivity of several instruments in the vicinity of full health. The EQ-5D and HUI 3 registered the largest number with the maximum score (91 and 59). In contrast AQoL-8D measured only 7 (Figure 1). The results suggested that the AQoL-8D is more appropriate in measuring QoL of Bangladeshi migrants.

Tests of instrument content have not been well developed in the literature and this report experimented with a number of methods to distinguish between the relative sensitivity of instruments. The limited range of health states means that these results cannot be taken as indicative of instrument sensitivity in particular disease areas.

The benefits of the study are threefold. Firstly, the results provide a basis for comparison for future investigation of the Bangladeshi community. Secondly, it will assist future researchers decide which instruments are most applicable in such studies of communities. Finally, the outcomes of this study will help government at local, regional and national level to determine appropriate policy goals for improving QoL of small ethnic communities in a multicultural society.In this regard results with respect to QALYs will assist policy makers estimate the cost effectiveness of measures affecting BMI and distress when its target their budget to improve QoL of this small ethnic community.

\section{Conclusion}

This study was a pilot for a larger study of the Australian population. Nevertheless it had the additional benefit of obtaining a description of health related characteristics of an ethnic community - Bangladeshi migrants. It used utility weighted and unweightedQoL instruments and new sensitivity tests. It provides both baseline information about this community and statistically significant results with respect to the multi-instrument comparisons. Referring to the three aims of the paper, it firstly provided a comparison of the Bangladeshi community with the Australian community, and found that $91 \%$ of Bangladeshi migrants were highly qualified $12 \%$ unemployed and that the majority maintained family ties and ethnic cuisine. Very few drink alcohol, virtually no women and few men smoke but a higher proportion have 'high' or 'very high' levels of psychological distress and are overweight. Secondly the paper explored different aspects of the Bangladeshi community, focusing in particular on the process of social adaptation, finding that this is multifarious and in terms of progress non-uniform. Finally, it compared the effectiveness of a number of multi attribute instruments for measuring the quality of life among Bangladeshi migrants in Australia. It found that, even amongst a relatively homogeneous population instruments differ significantly in both 'utility' scores and content.

\section{Acknowledgement}

This is an edited version of an early working paper ((Khan \& Richardson, 2011) which is available in CHE website.

\section{References}

AIHW. (2010). Australia's Health 2010. Canberra, Australian Institute of Health and Welfare.

Benfante, R. (1992). Studies of cardiovascular disease and cause-specific mortality trends in Japanese-American men living in Hawaii and risk factor comparisons with other Japanese populations in the Pacific Region: a review. Human Biology, 64(6), 791-805.

Brazier, J., Roberts, J., Tsuchiya, A., \& Busschbach, J. (2004). A comparison of the EQ-5D and Sf-6D across seven patient groups. Health Economics, 13, 873-884. http://dx.doi.org/10.1002/hec.866

Burns, N., \& Grove, S. (2001). The Practice of Nursing Research Conduct, Critiqe and Utilisation. Sydney, WB Saunders Company.

EuroQoL Group. (1990). EuroQol - a new facility for the measurement of health-related quality of life. Health Policy, 16, 199-208. http://dx.doi.org/10.1016/0168-8510(90)90421-9

Hawthorne, G., Richardson, J., \& Day, N. (2003). A Comparison of Five multi Attribute Utility Instruments. Working Paper 140. Melbourne, Health Economics Unit, Monash University. Retrieved from 
http://www.buseco.monash.edu.au/centres/che/pubs/wp140.pdf

Khan, M. (2003). Occupational Adjustment and Job Transition of South Asian Migrants in Melbourne. The Oriental Geographer, 47(1). Bangladesh Geographical Society, Dhaka.

Khan, M., \& Richardson, J. (2011). A Comparison of 7 instruments in a small general population. Research Paper 60, Melbourne, Centre for Health Economics, Monash University. Retrieved from http://www.buseco.monash.edu.au/centres/che/pubs/researchpaper60.pdf

Munib, A. (2006). The effects of immigration and resettlement on the mental health of South-Asian communities in Melbourne. Department of Psychiatry, Faculty of Medicine, Dentistry and Health Sciences. Melbourne, The University of Melbourne, Australia.

MuseumVictoria. (2009). Retrieved from http://museumvictoria.com.au/origins/getpopulation.aspx?pid=4

O’Donnell, C. R., Tharp, R. G., \& Wilson, K. (1993). Activity settings as the unit of analysis: A theoretical basis for community Intervention and development. American Journal of Community Psychology, 21, 501-520. http://dx.doi.org/10.1007/BF00942157

Pudaric, S., Sundquist, J., \& Johansson, S. E. (2000). Major risk factors for cardiovascular disease in elderly migrants in Sweden. Ethnicity and Health, 5(2), 137-150. http://dx.doi.org/10.1080/713667448

Sanchez-Vaznaugh, E., Kawachi, I., Subramanian S. V., Sánchez, B. N., \& Acevedo-Garcia, D. (2008). Differential effect of birthplace and length of residence on body mass index (BMI) by education, gender and race/ethnicity. Social Science and Medicine, 67, 1300-1310. http://dx.doi.org/10.1016/j.socscimed.2008.06.015

Sarmiento, J. (1991). The Asian Experience in International Migration. International Migration, 29(2). http://dx.doi.org/10.1111/j.1468-2435.1991.tb01014.x

Singh, G., \& Siahpush, M. (2001). All-cause and cause-specific mortality of immigrants and native born in the United States. American Journal of Public Health, 91, 392. http://dx.doi.org/10.2105/AJPH.91.3.392

Sonn, C. (2002). Immigrant Adaptation: Understanding the process through sense of community. Perth, Australia, Edith Cowan University.

Torrance, G. (1986). Measurement of health state utilities for economic appraisal: a review. Journal of Health Economics, 5, 1-30. http://dx.doi.org/10.1016/0167-6296(86)90020-2

\section{Copyrights}

Copyright for this article is retained by the author(s), with first publication rights granted to the journal.

This is an open-access article distributed under the terms and conditions of the Creative Commons Attribution license (http://creativecommons.org/licenses/by/3.0/). 